\title{
Editorial
}

Journal of Direct, Data and Digital Marketing Practice (2010) 12, 113-114. doi:10.1057/dddmp.2010.36

Two of our contributors have been considering recently performing a word-count on past articles we have published, in order to determine whether (or how) the frequency of appearance of particular significant words has changed in our authors' usage, and to speculate on what this may mean in the recent development of marketing practice. We hope to be able to print a report on this project in the near future.

Meanwhile, it will not have escaped readers' notice that certain words — or word pairs — have been recurring with much greater frequency in the past couple of years - not just in this journal, but across the trade media and lecture circuit: customer-centricity, customer retention, customer focus, customer engagement, and the like.

The principles embodied in these terms seem to be well-accepted. It is understood that internet search, web browsing, comparison websites, portals and word-of-mouse in social media have shifted the balance of power from producer to consumer; that a study of how consumers wish to buy may be a deal more important than how producers wish to sell; ${ }^{1}$ that retaining customers is the name of the game, ${ }^{2}$ and that this means paying attention to what they say.

But recognizing a principle is one thing; putting it into practice is altogether another. What is it that we have to do (or not do) to ensure that we have a customer-friendly organization?

The obvious place to start is with the organization's customer touch-points - the shop floor, the telephone, the website and its various landing pages, the email inbox, written correspondence, social network interactions. In many (most?) organizations, these touch-points are looked after by different staff, reporting in different departments, and operating with different criteria; in not a few these staff have no access to a common comprehensive view of the organization's customers; in some, one or more of these touch-points will have been outsourced, or even off-shored.

Let's be clear: no company that expects its most sensitive dealings with its customers to be handled by another party can conceivably claim to have a customer focus, to be customer-centric, or to be engaging its customers in meaningful dialogue. In a properly customer-centric company, those personnel who are in day-to-day contact with customers are, and will be seen to be, among the most important staff members outside (or possibly including) the CEO's office.

Of course, in a multimedia environment it is unlikely that all customer-facing staff will have the same skills across all media. But all should share the same comprehensive customer data, and should operate to the same criteria, and, so far as possible, to the same management. Such staff should be highly trained, and should have the widest discretion in how to deal (within corporate policy) with customer queries and complaints; it follows that they should be highly remunerated. The days of low-paid clerical staff marking up and sending out to each customer the most appropriate of 263 form letters are over: if one-to-one marketing means anything (and we do sometimes doubt it), then it means one person dealing sensibly and sensitively with another person's concerns.

Of course, that doesn't mean outlawing either the form letter or its modern descendants - the dreaded telephone menu, or the list of FAQs on the web. But when deploying these devices, it is essential to ask whether the telephone menu allows for the non-standard query, which doesn't fit any of the pre-set options; whether recourse to a real intelligent person is readily available to customers with an infrequently asked query, and so on. ${ }^{3}$

Alan Mitchell presents us in this number with a fascinating picture of the future of consumer power, ${ }^{4}$ when consumers will be able to control the collection and distribution of comprehensive 


\section{桨 Editorial}

information about themselves and their precise requirements. If (when) this revolution comes about, consumers will not be at all interested in handing out such information to companies that hide behind staircases of interlocking telephone menus, or dead-end self-help web screens. Customer focus means right now — and with still greater intensity in Alan's brave new world — engaging where necessary (ie when the customer wants it) in person-to-person dialogue.

In addition to the contributions referred to above, we have this quarter an article by Andrew Starkey, giving the customer's take on e-retail, with particular reference to home delivery, and from Barry Leventhal an article on data mining. We have three short case studies, courtesy of the DMA, and our Legal and Regulatory slot features a piece from the Director-General of FEDMA on current data protection concerns in Europe. We conclude with a collection of Abstracts; due to shortage of space we will carry our Book Reviews forward to the next issue.

Robin Fairlie Derek Holder

\section{References}

1. See, among many others, Mitchell, A. 'The buyer-centred revolution', Journal of Direct, Data, and Digital Marketing Practice, Vol. 5, No. 4.

2. See Merlin Stone et al in this issue.

3. See Graeme Foux in this issue, under 'Customer Support'.

4. See Alan Mitchell in this issue. 